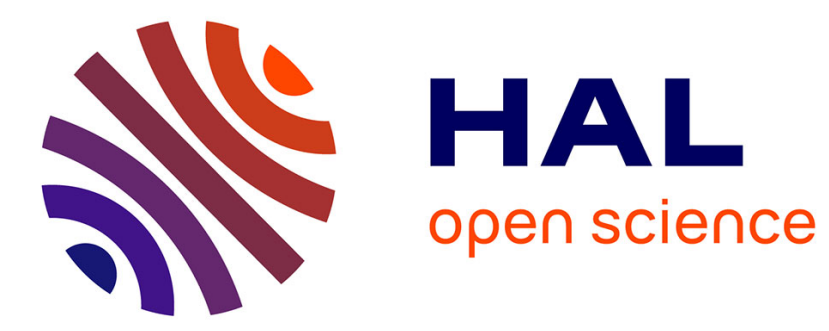

\title{
LASER INDUCED HYDROGEN MOTION IN ORGANIC CRYSTALS AT LOW TEMPERATURE
}

S. Astilean, R. Casalegno, A. Corval, H. Trommsdorff

\section{To cite this version:}

S. Astilean, R. Casalegno, A. Corval, H. Trommsdorff. LASER INDUCED HYDROGEN MOTION IN ORGANIC CRYSTALS AT LOW TEMPERATURE. Journal de Physique IV Proceedings, 1991, 01 (C7), pp.C7-451-C7-454. 10.1051/jp4:19917120 . jpa-00250770

\section{HAL Id: jpa-00250770 https://hal.science/jpa-00250770}

Submitted on 1 Jan 1991

HAL is a multi-disciplinary open access archive for the deposit and dissemination of scientific research documents, whether they are published or not. The documents may come from teaching and research institutions in France or abroad, or from public or private research centers.
L'archive ouverte pluridisciplinaire HAL, est destinée au dépôt et à la diffusion de documents scientifiques de niveau recherche, publiés ou non, émanant des établissements d'enseignement et de recherche français ou étrangers, des laboratoires publics ou privés. 


\title{
LASER INDUCED HYDROGEN MOTION IN ORGANIC CRYSTALS AT LOW TEMPERATURE
}

\author{
S. ASTILEAN, R. CASALEGNO, A. CORVAL and H.P. TROMMSDORFF \\ Laboratoire de Spectrométrie Physique associé au C.N.R.S., Université Joseph Fourier, BP. 87, \\ F-38402 Saint Martin d'Hères cedex, France
}

\begin{abstract}
.
We study here a laser induced reaction leading to a rearrangement of the acid protons in benzoic acid crystals at very low temperature. This hydrogen motion results from the electronlc excitation of pentacene molecules substitutionally included into a benzoic acid host matrix, protonated or deuterated. The growth of a deuterated benzoic acid crystal doped with pentacene leads to a partial deuteration of pentacene molecules, resulting in several origin bands in the absorption spectrum. The dynamics of the system following non selective and selective laser irradiations of the differently deuterated pentacene molecules is analyzed in terms of hydrogen rearrangements.
\end{abstract}

\section{Introduction.}

Hydrogen motion in solids at low temperature is intensively studied with a wide variety of methods. Among them, optical spectroscopy is a very sensitive one, specially when performed on crystals giving narrow spectral lines. Carboxylic acid crystals represent a class of model systems commonly used for studies on proton transfer /1-5/. In such a system where two molecules associate to form a dimer bound by two hydrogen bonds, the hydrogen motion consists in a double exchange of the acid protons along the two hydrogen bonds giving rise to a tautomer form. For an isolated dimer the two tautomer forms are identical and the potential energy may be represented by a symmetrical double well. In the crystal the two forms are no longer equivalent and the double well becomes asymetric, modifying the protons dynamics. An optical way of monitoring the proton movement is to replace a dimer by a dye impurity: any change in the dye environment, a tautomerization in the neighboring dimer for example, is reflected in its absorption spectrum. A particularly interesting feature of such a system is that the optical excitation of the dye molecule induces the desired environmental change which is then probed using the same dye molecule. By such a method, it was possible to study the protons tunneling mechanism in mixed thioindigo/benzoic acid crystals at very low temperature $/ 6 /$.

In the system studied here, composed of benzoic acid (BA) as the matrix and pentacene (PC) as the impurity, it has been proved that the induced modification of the neighborhood was not a double proton exchange but a more severe rearrangement $17 /$. This conclusion was drawn from the fact that the induced changes were very long-lived $(10$ orders of magnitude Ionger than in the tautomerization case), and that the energy difference between the two states was at least 30 times larger than the one reported in the literature for a tautomerization in a BA crystal /8/. A proposed mechanism was an 
opening of an hydrogen bond followed by a reorientation of the $0-H$ bond, or even an exchange of a proton between the matrix and its host. A decisive test for these questions was a deuteration of the benzoic acid. We present here some results on the effect of this deuteration on the absorption spectrum of pentacene. They first show that a deuteration of pentacene is already performed during the crystal growth and can be clearly analyzed /9/, and that the lifetimes of the photoproducts obtained after laser irradiation are lengthened by about two orders of magnitude. Moreover selective irradiations on the differently deuterated pentacene molecules indicate that they behave differently with respect to their environment.

Sample preparation and deuteration.

During the growth of the mixed PC/d-BA (d for deuterated) crystal by standard Bridgman technique a partial deuteration takes place, and according to the duration of the crystal growth it is possible to get PC molecules where at maximum 6 hydrogens have been replaced by deuteriums. These substitutions are imaged on fig.1, showing the absorption spectra in the origin region of crystals grown during $0.5,2$ and 6 days. The different lines are labelled $D_{0}, D_{2}, \ldots, D_{s}$ for pentacene molecules bearing 0 to 6 deuteriums.

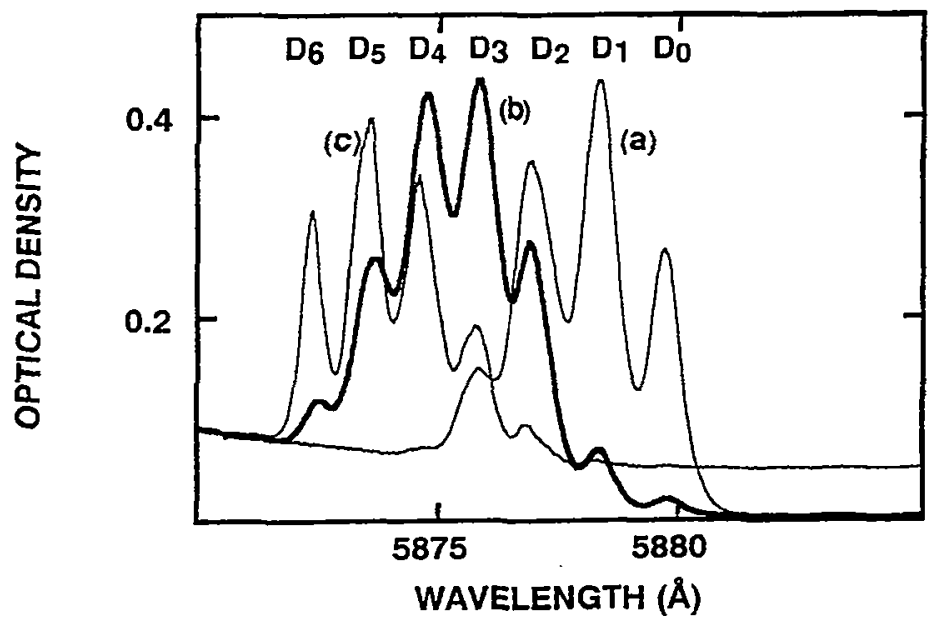

Figure 1 : Absorption spectra of partially deuterated pentacene in deuterated benzoic acid at $1.6 \mathrm{~K}$, after (a): half a day, (b): 2 days, (c): 6 days of crystal growth.

This particular feature allows to prepare samples containing more or less deuterated PC molecules and gives the interesting possibility to selectively excite a chosen $D_{1}$ class of PC molecules.

Selective and non-selective laser irradiations.

Two types of laser irradiations have been performed: selective ones, as described above, achieved with a spectrally narrowed dye laser(FWHM $1 \mathrm{~cm}^{-}$ 2), or non-selective ones using the $514 \mathrm{~nm} \mathrm{Ar^{+ }}$ laser Iine. In the latter case the photon energy is high enough to excite simultaneously the seven class of PC moiecules defined previously.

Fig.2 shows the absorption spectra of a crystal grown during 2 days recorded before and after a non-selective laser irradiation. On the lower trace are only visible the 7 origin lines of the non-irradiated pc molecules. 
On the upper trace clearly appear several sets of lines reproducing more or less faithfully the origin set. Each set is assigned to a photoproduct 1.e. a modification in the environment of the $\mathrm{PC}$ molecules, but two differently deuterated PC molecules contribute differentiy inside a given set. This behavour is deduced from fig.3 for which a selective irradiation was applied to the $D_{6}$ line of a crystal grown 6 days: the position of the different $D_{0}-$ photoproducts may be used to find their positions in the sets of fig.2, and then to determine the positions of the other $D_{1}$ photoproducts in the same set.

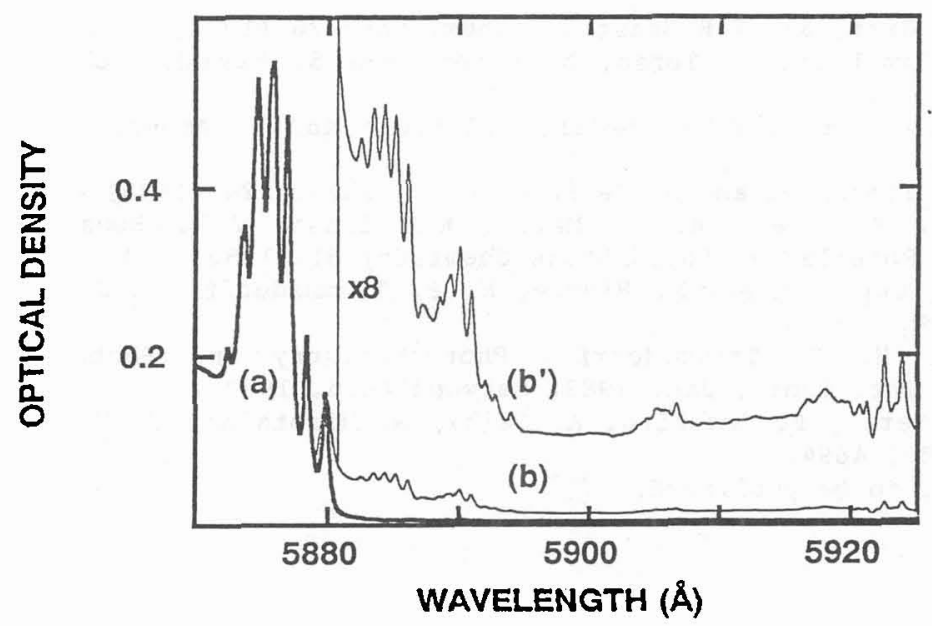

Figure 2 : Absorption spectra of d-pentacene in d-benzoic acid at $1.6 \mathrm{~K}$, (a) before irradiation, (b) after non selective irradiation with the $5145 \mathrm{~A}$ line of an $\mathrm{Ar}^{+}$laser; (b') is a $8 x$ expansion of (b), arbitrarily shifted on the D.O. scale for better clarity.

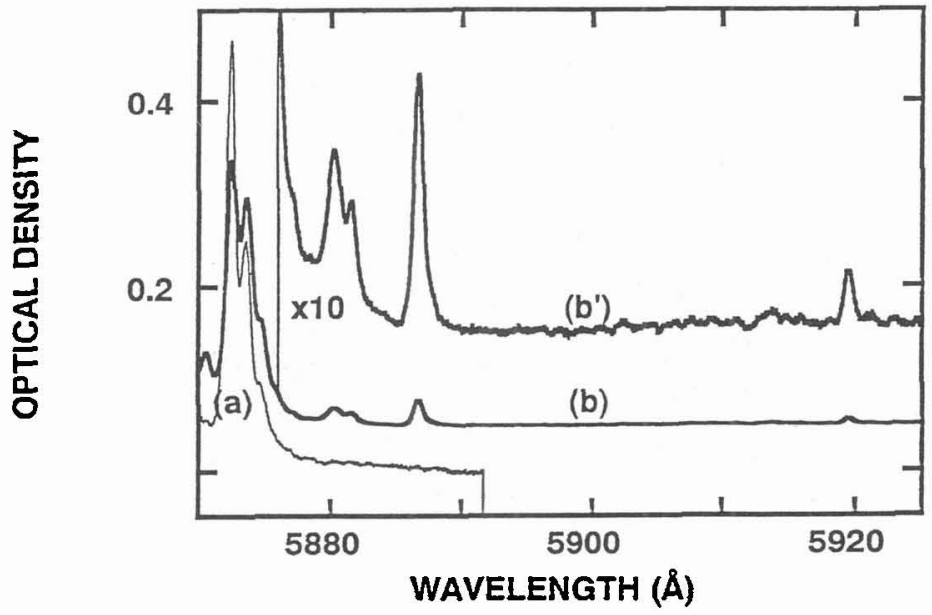

Figure 3 : Absorption spectra of d-pentacene in d-benzoic acid at $1.6 \mathrm{~K}$ (a) before irradiation, (b) after selective excitation of the $D_{6}$ origin line; (b') is a $10 x$ expansion of (b).

(b) and (b') are aibitrarily shifted on the D.O. scale. 
Lifetime measurements have been done on the photoproducts obtained under selective irradiation. They gave lifetimes of 100 to 500 hours, more than 100 times longer than the lifetimes measured in a protonated matrix.

All these results confirm the role of the acid proton in the formation of the photoproducts seen on the PC absorption spectra. The exact nature of formation process is still not understood but new informations will be given by further selective irradiations of the $D_{0}$ to $D_{s}$ origin lines.

References.

/1/ B.H. Meler, F. Graf, and R.R Ernst, J. Chem. Phys 76 (1982) 767.

$12 / \mathrm{T}$. Agaki, F. Imashiro, T. Terao, N. Hirota and S. Hayashi, Chem. Phys. Letters 139 (1987) 331.

/3/ A. Stoeckli, A. Furrer, B. H. Meier, R.R Ernst and I. Anderson, Physica $136 \mathrm{~B}, 161(1986)$.

/4/ F. Fillaux, J. Tomkinson and J. Penfold, Chem. Phys. 124 (1988) 425.

$15 /$ P. Fisher, P. Zolliket, B. H. Meier, R.R Ernst, A.W. Hewat, J. D. Jorgensen and F.J. Rotella, J. Solid State Chemistry 61 (1986) 109.

$\mid 6 /$ C. Rambaud, A. Oppenlunder, M. Pierre, H. P. Tromsdorff and J. C. Vial, Chem. Phys. 136 (1989) 335.

/7/ R. Casalegno, H. P. Trommsdorff, "Photochemistry and Photobiology", Proceedings of the Int. Conf., Jan. 1983, Harwood Acad. 1983.

/8/ S.Nagaoka, T. Terao, F. Imashiro, A. Saika, N. Hirota and S. Hayashi, J. Chem. Phys. 79 (1983) 4694.

$19 /$ A.Corval et al., to be published. 